\title{
GENERAL CHARACTERISTICS FOR LOADING THE WORKING ELEMENTS OF DRILLING AND MILLING MACHINES WHEN MOVING IN THE CLAY SOLUTION
}

\author{
Adil Kadyrov $^{1}$, Zhanara Zhunusbekova ${ }^{1, *}$, Aleksandr Ganyukov ${ }^{1}$, Irina Kadyrova ${ }^{2}$, Aliya Kukesheva ${ }^{1}$ \\ ${ }^{1}$ Karaganda State Technical University, Karaganda, Kazakhstan \\ ${ }^{2}$ Karaganda State Medical University, Karaganda, Kazakhstan \\ *E-mail of corresponding author: zhzhzh_84@mail.ru
}

\section{Resume}

The article is devoted to influence of the clay thixotropic solutions on the strength of resistance to movement of the earthmoving machines' working elements.

The forces of resistance to the movement of a flat plate, a smooth cylinder and real working bodies in a clay solution for various modes of solution flow (bingamian, pseudo-laminar and turbulent) are established.

Mathematical models of movement of the earthmoving machines working elements in clay solution are developed and investigated.

Dynamics of the working element of an earthmoving machine movement in a clay solution is studied. Dependence of the feed force, torque and dynamic coefficient on the resistance forces, acting on the working body from the clay solution, is established.

\section{Article info}

Received 17 May 2020

Accepted 19 July 2020

Online 19 January 2021

\section{Keywords:}

clay solution,

working element, resistance to movement, motion mode, loading, earthmoving machines

\section{Introduction}

During the construction of buried structures using the diaphragm wall method, the excavation works, as usual, are performed under the clay thixotropic solution There is a hypothesis that additional loading affects the working element (hereinafter referred to as WE) of a trench digger moving in the clay solution [1-2].

This method has already become quite widespread, both in Kazakhstan and abroad in construction of industrial, civil, hydraulic, transport and agricultural facilities. Effectiveness of the "wall in the ground" method depends on the hydro-geological conditions of the construction site, the costs of equipment for performing the work, characteristics of the structure being built and other factors. This method is more promising for reconstruction of enterprises and construction of underground structures in urban development near the existing buildings. The practice of building production has shown that the subsequent development of construction using the "wall in the ground" method is possible only when using machines of mechanical and hydro-mechanical action [3].

Therefore, the study of the working parts loading of earthmoving machines, operated in the clay thixotropic solution, is an urgent task.

Resistance of solids when moving in fluid (flow with fluid) can be characterized with the friction force (T), the hydrodynamic head resistance $P_{h d}$ and the buoyancy force $\mathrm{P}_{\mathrm{b}}$ and in the general case, the following equation can be written:

$R_{r e s}=T-P_{h d}-P_{b}$,

where $R_{\text {res }}$ is the resistance total force to the WE moving in mud.

\section{Material and methods}

To define the resistance value to the WE moving in the clay solution, it is theoretically and experimentally necessary to determine the values and patterns of changes in the force variation $\mathrm{T}$ and $P_{h d}$, when the mud in motion is relative to the WE in the Swedish, Bingham and pseudolaminar conditions. Operation of the excavating machines at speeds causing the turbulent movement of the mud is undesirable since there is a possibility for an increase in the WE dynamics [3-4].

At the first stage of the study, the motion of a smooth plate measuring $F$ and a provided small thickness $\Delta$ and a smooth cylinder with the radius Rand the length $L . \backslash$ is considered. Then, it is proceed to defining the loading of the WE of excavating machines, which are complex elements in its configuration. 
The motion of a thin plate in the clay thixotropic solution is considered, which may be forward, rotation and compound. If the velocity vector lies in the plate plane, the resistance to motion is determined by the friction force $\mathrm{T}$ arising on the side surfaces of the plate and the buoyancy force $\mathrm{P}_{0}$. The hydrodynamic resistance due to the infinite small thickness of the plate can be neglected.

The value of the total drag force $\mathrm{R}_{c}$ for various flow conditions of the mud will be different, this is due to a change in its rheology depending on the flow velocity. For the Swedish conditions, taking into account the BinghamKelvin model, the following is true:

- $\quad$ during the plate vertical motion:

$R_{\text {res }}=F=\frac{\eta_{1} E_{1} E_{2}+\sigma_{0} t E_{1} E_{2}}{\left[E_{1}\left(1-e^{\frac{t}{t 0}}\right)+E\right] \eta_{1}+t E_{1} E_{2}}-m_{n} g$

where:

$m_{n}$ - plate mass;

$\eta$ - relaxation viscosity;

$e$ - relative strain;

$E_{1}$ - initial conditional instantaneous shear modulus;

$E_{2}$ - elasticity modulus;

$\sigma_{0}$ - elastic limit, below which the residual deformations cannot be developed;

$t$ - time;

$t_{\mathrm{o}}$ - relaxation time.

and

- when the plate moves in the horizontal direction and zero buoyancy:

$R_{\text {res }}=F=\frac{\eta_{1} E_{1} E_{2}+\sigma_{0} t E_{1} E_{2}}{\left[E_{1}\left(1-e^{\frac{t}{t_{0}}}\right)+E\right] \eta_{1}+t E_{1} E_{2}}$.

The friction force with the plate motion, at a speed causing appearance of the Bingham conditions of fluid flow, can be determined by the following dependence:

$T=F \tau=F\left(\tau_{0} \pm \eta \frac{d U}{d \delta_{T}}\right)$,

where:

$\tau$ - shear stress;

$\tau_{0}$ - yield stress.

The "plus" or "minus" sign is used depending on the velocity gradient sign taking into account the requirement to make positive the specific force direction $\tau$.

In the straight line motion of the plate in the clay solution, its speed is equal to the speed of the flow core, which follows from the added masses theory. Considering the $\Delta \rho=0$, what corresponds to our case, one obtains:

$U=-\frac{\tau_{0}}{\eta}\left(H_{g}-\delta_{T}\right)$,

where:

$U$ - fluid motion speed;

$H_{g}$ - maximum distance from the plate;

$\delta_{T}$ - boundary-layer thickness;

$\eta$ - plastic viscosity.

Then the plate velocity gradient in the following: $\frac{d U}{d \delta_{T}}=\frac{\tau_{0}}{\eta}$

and the friction force under the condition $V_{n}=U_{\max }$ can be determined by the following formula:

$T=F \tau=F\left(\tau_{0}+\eta \frac{d V}{d n}\right)=2 F \tau_{0}$.

In the pseudo-laminar conditions of motion the rheological properties of the clay solution are adequate to the rheological properties of an ordinary viscous fluid. The velocity-distribution law of viscous the fluid flow has a parabolic nature:

$U=U_{\max }\left(1-\left(\frac{\delta_{T}}{H_{g}}\right)^{2}\right)$.

The plate velocity gradient:

$\frac{d U}{d n}=-2 U_{\max } \frac{\delta_{T}}{H_{g}}$

and the plate friction force in the mud can be determined by the following formula:

$\left.T=F \tau= \pm 2 F \mu_{p} \frac{d U}{d n}= \pm 2 F \mu_{p} U_{\max } \frac{\delta_{T}}{H_{\max }}\right)$,

where:

$\mu_{p}$ - dynamic viscosity.

The maximum value of the friction force corresponds to equality of values $H_{g}$ and $\delta_{T}$, in this case:

$T_{\max }= \pm 2 F \mu_{p} \frac{U}{H_{g}}$.

Assuming the motion speed for the mud flow to be equal to the speed of the plate motion, one obtains:

$T_{\max }= \pm 2 F \mu_{p} \frac{V_{n}}{H_{g}}$.

In the stream core of the turbulent flowwith the developed turbulence speed the fluid flow changes according to the logarithmic law:

$U=\frac{U^{*} \ln \delta_{T}}{\beta+c}$,

where:

$U^{*}$-dynamic velocity or the fluid cutting speed;

$\beta$ - constant Prandtl, $\beta=0.360 \ldots 0.436$ [5]

$\mathrm{C}$ - constant value.

The plate velocity gradient is:

$\frac{d U}{d \delta_{T}}=\frac{U^{*}}{\beta \delta_{T}}$.

Then, taking into account the shear function during turbulent motion of the mud [6], one gets:

$\tau=\mu_{f} \frac{d U}{d \delta_{T}}+p_{c} l^{2} \frac{d U^{2}}{d \delta_{T}}=U^{*}\left[\frac{\mu_{f}}{l}+p_{c} l\left(U^{*}\right)^{2}\right]$,

where: 


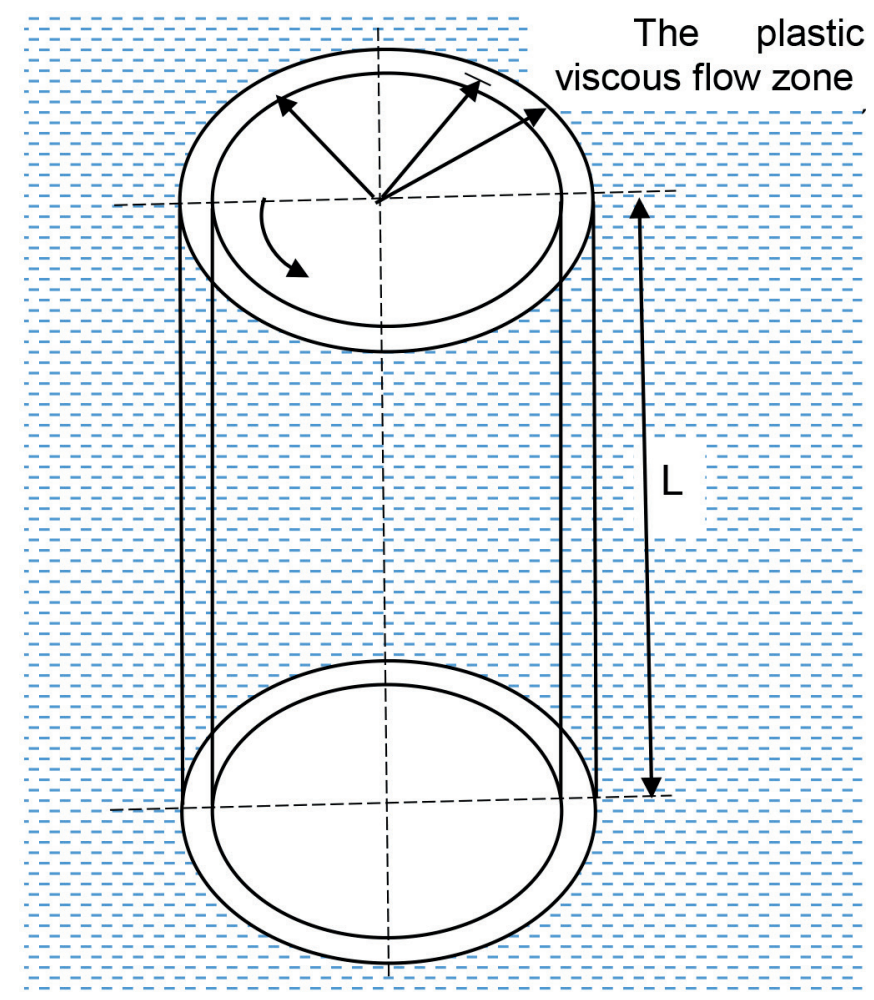

Figure 1 The nature of the flow solution around a rotating smooth cylinder

$\mu_{\phi}$-fictitious velocity.

$$
T=F \tau=F \frac{U^{*}}{l}\left(\mu_{f}+p_{c} l U^{*}\right)
$$

Moreover, as it appears from the theory of the turbulent motion that $l=\beta \delta_{T}$. When the plate rotates around the horizontal or vertical axis, the moment $M_{c}$ from the resistance force to motion is determined in the general case by the following dependence:

$$
M_{\text {res }}=\left[P_{g d}+T+\left(P_{b}-m g\right) \sin \varphi\right] R,
$$

where:

$\varphi$ - plate rotation angle about axis of rotation.

In the case of the plate complex motion, when determining its speed, it is necessary to take into account the value of the angle $\alpha$ between the portable $\vartheta$ and relative $\omega R$ speeds:

$\alpha=\operatorname{arctg} \frac{V}{\omega R}$.

For excavating machines (drilling and milling), as a rule, the portable speed is for one or two orders of magnitude less than the relative, and the value of the $\alpha$ angle does not exceed 2 to $3^{\circ}$. The dependences obtained for the plate complex motion are summarized in Table1. The same expression (17) is presented as concretized for each mode of the mud motion.

Thus, there have been obtained the formulas for determining the friction forces for each possible motion conditions of the clay thixotropic solution. The following conclusions have been made:
1. During the Swedish conditions of the clay solution motion the resistance to the plate motion is provided by occurring of elastic strains.

2. The plate loading under the Bingham conditions of the mud flow is characterized by its ultimate shear stress $\tau_{0}$.

3. The resistance to the plate motion during the pseudolaminar motion of the mud depends on the mud viscosity and its speed.

4. In the turbulent conditions of motion, the resistance force to the plate motion depends on the core size of the flow stream, the medium density, and the fictitious viscosity value.

The smooth cylinder motion (rotational and compound) of the radius $\mathrm{R}$ and the length $\mathrm{L}$ in the clay thixotropic solution is considered. The cylinder is brought into rotation from a state of rest with an angular velocity $\omega$.

When the cylinder moves at a speed that determines the Swedish conditions of the mud flow, the moment from the resistance force is determined taking into account Equation (3): $\mathrm{M}_{\text {res }}=\mathrm{R}_{\mathrm{c}} \mathrm{R}$.

The Bingham fluid flow zone extends only to a finite distance from the rotating cylinder (Figure 1). The rest of the mud will be at rest. A very thin laminar layer forms around the cylinder, behind which there is a zone of the plastic viscous flow. The radius of the plastic viscous flow zone and the fluid velocity are related. When the vector radius $r$ is equal to the radius of extent of the plastic viscous flow zone $r_{t}$, the mud velocity is zero and if the values $r=R$ are equal, the mud velocity is maximum [7-8].

The gradient of the normal shear velocity: 


$$
U=\frac{\tau_{0}}{2 \eta} r\left(\left(\frac{r_{T}}{r}\right)^{2}-1-\ln \left(\frac{r_{T}}{r}\right)^{2}\right),
$$

is:

$$
\frac{d U}{d r}=\frac{\tau_{0}}{2 \eta}\left(1-\left(\frac{r_{T}}{r}\right)^{2}-\ln \left(\frac{r_{T}}{r}\right)^{2}\right) .
$$

The resistance moment to the cylinder rotation in the clay thixotropic solution with the steady Bingham conditions, taking into account Equation (20) is expressed by the system of equations:

$$
\begin{aligned}
M_{\text {res }} & =2 \pi R^{2} L\left(\tau_{0} \pm \eta \frac{d U}{d r}\right)= \\
& =\left\{\begin{array}{l}
\pi R^{2} L \tau_{0}\left[3-\frac{r_{T}}{r^{2}}-\ln \left(\frac{r_{T}}{r}\right)^{2}\right] . \\
\pi R^{2} L \tau_{0}\left[1+\frac{r_{T}^{2}}{r^{2}}-\ln \left(\frac{r_{T}}{r}\right)^{2}\right]
\end{array}\right.
\end{aligned}
$$

In the further studies, the maximum value of the moment, corresponding to the sum of the ultimate shear stress and the product of structural viscosity by the velocity gradient is taken, with the fulfillment of the equality $r=R$ Thus one obtains:

$$
M_{\text {res }}=2 \pi R^{2} L \tau_{0}\left[3-\frac{r_{T}^{2}}{R}-\ln \frac{r_{T}^{2}}{R}\right] .
$$

Transforming the series of the Maclaurinequation:

$M_{\text {res }}=3+A r w+B r w^{2}$,

where:

$A_{r}$ and $B_{r}$ - coefficients of the Maclaurin's series.

Introduction of $\mathrm{A}_{\mathrm{r}}$ and $\mathrm{B}_{\mathrm{r}}$ is required only for the further mathematical analysis.

In Equation (23), the cylinder rotation resistance moment under the Bingham conditions of the mud flow depends on the cylinder dimensions, the ultimate shear stress, and the radius of extent of the flow zone. The radius $\mathrm{r}_{\mathrm{T}}$ is a function of the mud rheological characteristics and the cylinder angular velocity.

In the pseudo-laminar flow mode, the Bingham fluid with rheological characteristics is adequate to a viscous fluid with a dynamic viscosity coefficient $\mu_{\rho}$. Rotation of the viscous fluid differs from rotation of a solid body in the fact that fluid performs a dynamic rotation, that is, particles of a fluid removed at a different distance from the rotation axis move with different angular velocities [9]. Wherein:

$U_{0} r=C=$ const

where:

$U_{0}$ - fluid circumference speed;

$\mathrm{C}$ - certain constant value.

Therefore, with moving of the mud particles away from the rotation axis, their circumference speed decreases due to the layered rotation and presence of friction between the layers. In the boundary layer $\omega R=\frac{C}{R}, C=\omega R^{2}$

The gradient of mud velocity:

$\frac{d U}{d r}=-\frac{C}{r^{2}}$.

The friction force on the cylinder surface taking into account the equality of the values $r$ and $R$ is determined by the following formula:

$T=F \tau= \pm 2 \pi R^{2} L \mu_{p} \frac{d U}{d r}= \pm 2 \pi R L \omega \mu_{p}$.

The moment from the resistive force is:

$M_{\text {res }}= \pm 2 \pi R^{2} L \omega \mu_{p}$

In the turbulent conditions of the mud flow, its resistance moment to rotation is the following:

$M_{\text {res }}=2 \pi R^{2} L \omega \mu_{p}$,

where:

$\tau$ is determined from Equation (16).

Having found the gradient of the mud velocity, one obtains:

$M_{\text {res }}=2 \pi R^{2} L \frac{U^{*}}{l}\left(\mu_{p}+\rho_{c} l U^{*}\right)$.

The compound motion of a smooth cylinder is analyzed next. The cylinder rotates with a constant angular velocity $\omega$ and moves with a feed speed $V$. Here $\omega R \geq V$ for the WE of excavating machines. In this regard, the resistance force to friction in rotational motion is significantly higher than the resistance force to friction in the translational motion. Therefore, with a high degree of accuracy, it is possible to use Equations (21) and (25) for calculations. If the values are comparable to values of the feed rate, it is necessary to take into account the angle $\alpha$ between the portable and relative speeds.

The calculation formulas obtained in this subsection Equations (22), (29), (31) are summarized in the Table1. The same Table shows dependencies for determining the resistance forces during the compound motion of a plate and a cylinder. Analysis of the obtained dependencies has allowed the following conclusions to be drawn:

In the Swedish conditions of the clay solution flow, the resistance to rotation of a cylinder is determined by the elastic properties of gel; in the Bingham conditions, it is determined by the ultimate shear resistance of the medium and the size of the plastic viscous flow zone, and in the case of the pseudo-laminar flow - by the mud dynamic viscosity and its rotation speed.

The cylinder loading during the rotation and the plate during its moving in the mud is generally carried out according to the same physical schemes.

The magnitude and nature of excavating machines loading when moving in the clay thixotropic solution 
Table 1 Dependencies for determining the resistance forces during the elementary bodies moving in the clay solution

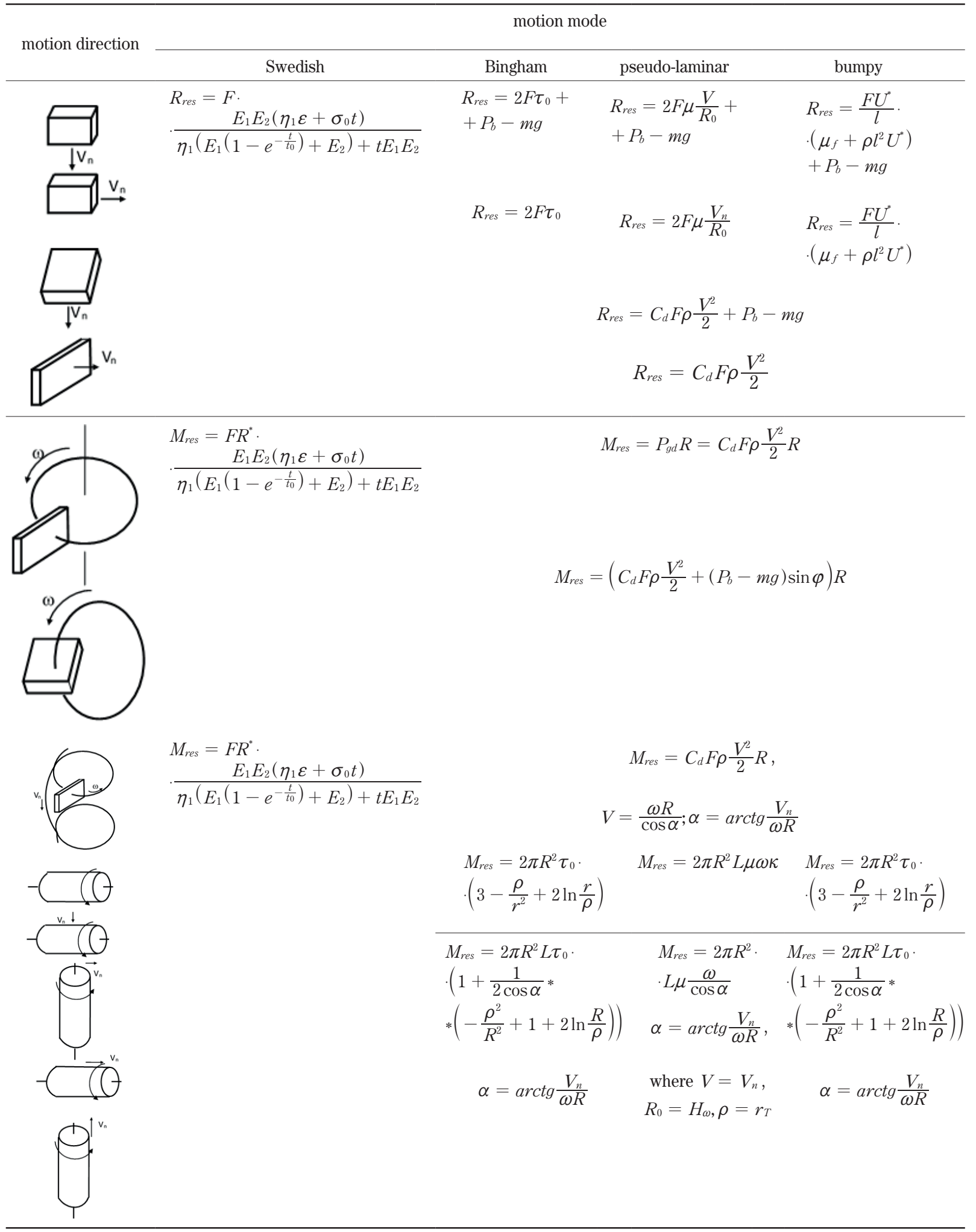

are further determined. To this end, one considers the movement of a hypothetical WE, which is affected by some resistance forces arising both during the cyclic machines operation and positional and continuous machines (milling, drilling bits) [10-11].

It is assumed that the WE is a combination of rotating and translationally moving elements. The rotation is carried out around the $\mathrm{Oz}$ and $\mathrm{Oy}$ axes and the rectilinear motion occurs in the zOy plane. The scheme of the adopted loading model of the $\mathrm{WE}$ is shown in Figure2. The $\mathrm{Oz}$ and Oy axes are instantaneous and directed along the bar and perpendicular to the WE bar. The decomposition principle allows any WE to lead to a combination of the translationally moving and rotating elements. A compound 


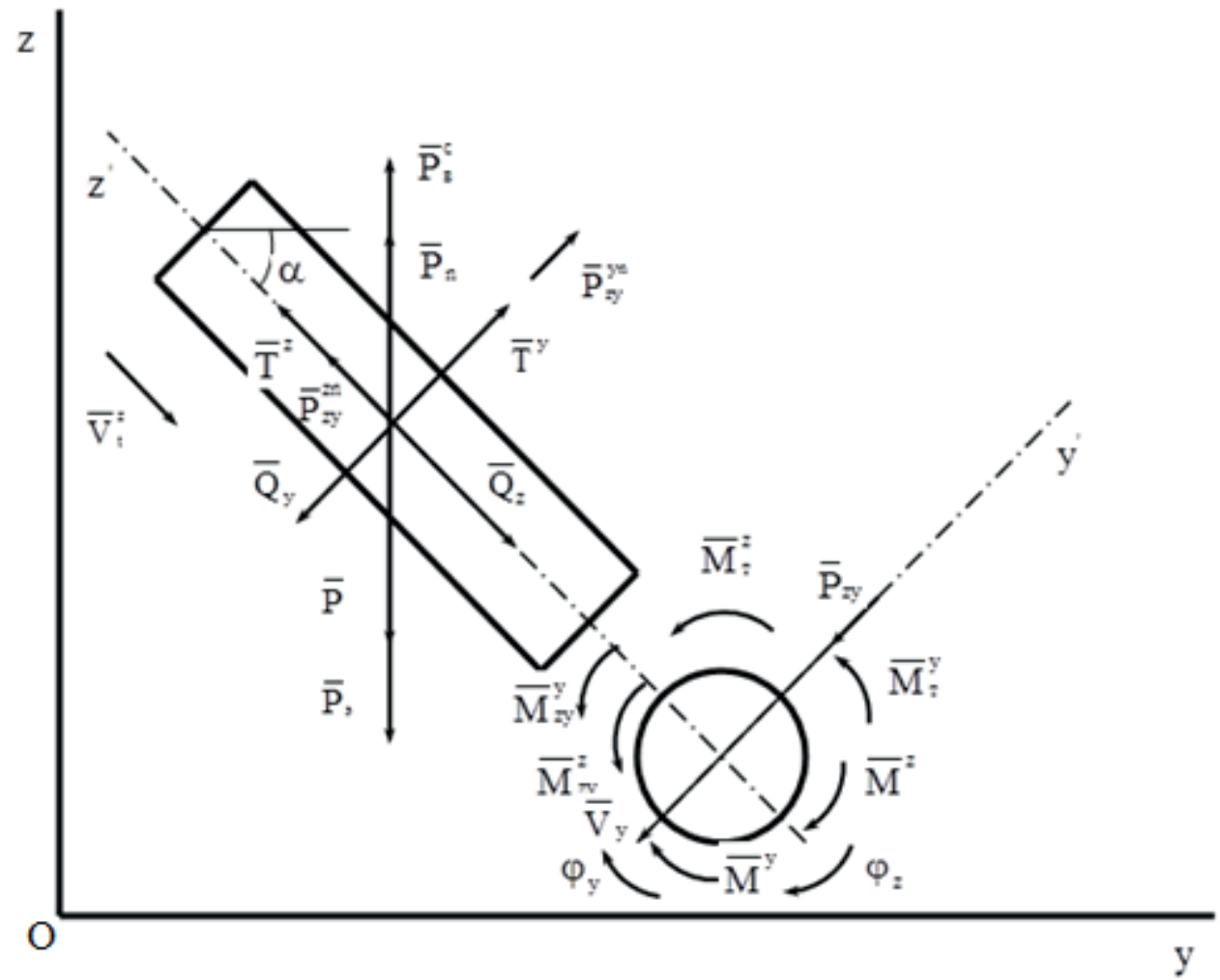

Figure 2 Generalized graphic model for the WE loading of excavating machines in the clay solution

motion of one element can be represented as the moving of the two elements performing translational and rotational movements [12].

The WE experiences a forward force $\mathrm{Q}\left(\mathrm{Q}^{\mathrm{z}}\right.$ and $\mathrm{Q}^{\mathrm{y}}$ but along the instantaneous axes), a rotational moment $\mathrm{M}\left(\mathrm{M}^{\mathrm{z}}\right.$ and $\mathrm{M}^{\mathrm{y}}$ when rorating around the instantaneous axises); a buoyancy force $P_{n}^{c}$; a gravity force $P$ : frictional resistance of moving forward elements of the WE against the mud $\mathrm{T}\left(\mathrm{T}^{\mathrm{zn}}, \mathrm{T}^{\mathrm{yn}}\right) ;$ a hydrodynamic drag force $\mathrm{P}_{\mathrm{gd}} \cdot\left(P_{g d}^{z n}, P_{g d}^{\mathrm{yn}}\right)$; a reaction force on the conveyor side $\mathrm{P}_{z}$, a lifting force arising as a result of the WE rotation $\mathrm{P}_{\mathrm{n}}$; a moment from the hydrodynamic force on the rotating flat cells $\mathrm{M}_{\mathrm{gd}}\left(M_{g d}^{\mathcal{z}}, M_{g d}^{y}\right)$, fractional moment against the mud when rotating a tool $\mathrm{M}_{\mathrm{T}},\left(M_{T}^{z}, M_{T}^{y}\right)$.

The friction and hydrodynamic drag forces are determined from Equations (3), (11), (17), (27), (31) and (32). The buoyancy force is described by formula consisting of a constant part and a term depending on the loading depth:

$P_{n}^{c}=P_{b}+K_{b} z=V \rho_{c} g+g z \rho_{c} P_{m}$,

where:

$\mathrm{P}_{\mathrm{b}}$ - buoyancy force affecting a part of the tool of a constant volume;

$\mathrm{K}_{\mathrm{b}}$ - the parameter equal to the product of the bar (rod) average section by the clay solution density;

V - WE tool volume;

$\mathrm{P}_{\mathrm{m}}$ - rod mid-section area.

For the WE mounted on a rod, the buoyancy force is determined by Equation (32) and for those suspended by a cable-block system, it is necessary to take into account the second term being equal to zero due to the rod absence [13].

The lifting force and reactive force from the conveyor (for example airlift) are expressed by the following dependencies:

$$
\begin{aligned}
& P_{n}=2 \pi \omega R \rho_{c} V F^{z b}, \\
& P_{c}=4 F_{c} \rho_{c}\left(V-V_{T}\right)^{2},
\end{aligned}
$$

where:

$\mathrm{F}^{\mathrm{zb}}$ - mid-section of rotating elements when they rotate around the axes;

$\mathrm{F}_{\mathrm{c}}$ - conveyor sectional area;

$\mathrm{V}_{\mathrm{T}}$ - pulp conveying speed.

The model does not have regard to Bjerknes and Coriolis forces due to their insignificance in magnitude, the WE is taken as a single-mass and completely rigid, there are no oscillations in the system. The WE loading model at the first stage was developed for the steady-state mode provided that the inertia force is equal to zero.

In the Swedish flow conditions, the clay solution is a gel-like body, with no buoyancy and lifting forces. This is due to the presence of structural bonds between the gel molecules [14]. The Swedish flow conditions model of the clay solution characterizes only the initial period of equipment operation after a long absence of exposure to the mud. The model is described by the following set of equations: 
Table 2 Values of forces and moments due to the resistance forces when the excavating machines' WEs move in the clay thixotropic solution

\begin{tabular}{cccccc}
\hline \multirow{2}{*}{ conditions } & \multicolumn{4}{c}{ loading parameter value } \\
\cline { 2 - 5 } & $\mathrm{H} \cdot \mathrm{m}$ & $\mathrm{H} \cdot \mathrm{m}$ & $\mathrm{H}$ & $\mathrm{H}$ & 103.6 \\
\hline Bingham & 15.7 & 275 & 200 & 4400 \\
Pseudo-laminar & 13.2 & 242 & 175 & 103.6 & 4400 \\
\hline
\end{tabular}

$\left\{\begin{array}{l}Q^{z}=F^{z n} \sigma \\ Q^{y}=F^{y n} \sigma\end{array}\right.$

$\int M^{z}=F^{z b} \sigma R$

$\left\{M^{y}=F^{y b} \sigma R\right\}$

where:

$\mathrm{F}^{\mathrm{zn}}$ and $\mathrm{F}^{\mathrm{zy}}$-respectively, the midsection areas with the WE motion direction along the $\mathrm{Oz}$ and $\mathrm{Oy}$ axes,

$\mathrm{F}^{\mathrm{yb}}$ - midsection of rotating elements when rotating around the $0 \mathrm{y} y$ axis.

For the Bingham, pseudo-laminar and turbulent conditions, the WE loading model has a formally adequate general form. This is explained by the effect on the $\mathrm{RO}$ of the same physical forces, that are only differed by various rheological characteristics of the clay solution. The WE loading model has the following form:

$$
\left\{\begin{array}{l}
Q^{z}=T^{z n}+P_{g d}^{z n}+\left(P_{n}+P_{b}+K_{b} z-P-P_{e}\right) \sin \alpha \\
Q^{y}=T^{y n}+P_{g d}^{y n}+\left(P_{n}+P_{b}+K_{b} y-P-P_{e}\right) \cos \alpha \\
M^{z}=M_{g d}^{z}+M_{T}^{z} \\
M^{y}=M_{g d}^{y}+M_{T}^{y}
\end{array}\right.
$$

The first and the second equations of Equations (37) differ only in the form of trigonometric function; the third and the fourth equations are similar. In this regard, further are considered only two equations passing to others, if necessary, by replacing the midsection along to the WE motion direction along the axis $O z$ to the $O y$, and changing $\sin \alpha$ to $\cos \alpha$.

Continuing with determination of the forces' values, included into Equations (36), one can write:

$$
\left\{\begin{array}{l}
Q^{z}=2 F^{z n} \tau_{0}+0,5 C_{d}^{n} \rho_{c}\left(V^{z n}\right)^{2}+(2 \pi \\
\cdot \omega R \rho_{c} V F^{z b}+P_{b}+P_{m} \rho_{c} g z-m g-4 F_{c} \rho_{c} \\
\left.\cdot\left(V-V_{t}\right)^{2}\right) \sin \alpha \\
M^{z}=0,5 C_{d}^{b} F^{z b} \rho_{c} \omega^{2} R^{2}+\pi R^{2} L \tau_{0} \\
\cdot\left(3+A_{r} \omega+B_{r} \omega^{2}\right)
\end{array}\right.
$$

where:

$C_{d}^{n}$ and $C_{d}^{b}$ - accordingly hydrodynamic coefficients with the translational and rotational motion of the WE in mud. For the pseudo-laminar conditions of the clay solution moving:

$$
\left\{\begin{array}{l}
Q^{2}=2 F^{z n} \mu_{p} V^{z} / H_{g}+0,5 C_{d}^{n} F^{z n} \rho_{c}\left(F^{z}\right)^{2}+ \\
+\left(2 \pi \omega R \rho_{c} V^{z} F^{z b}+P_{b}+P_{m} \rho_{c} g z-m g-\right. \\
\left.-4 F_{c} \rho_{c}\left(V-V_{T}\right)^{2}\right) \sin \alpha \\
M^{z}=0,5 C_{d}^{b} F^{z b} \rho_{c} \omega^{2} R^{3}+2 \pi R^{2} L \mu_{p} \omega
\end{array} .\right.
$$

In the turbulent conditions of the clay solution motion, to determine the WE loading in Equations (37), it is necessary to introduce the friction force that is defined by Equation (16). In this case, the general form of Equation (37) remains unchanged.

\section{$3 \quad$ Results}

The resulting equation systems allow determining the total resistance force acting on the excavating machines of various designs when moving in the clay solution. To establish the loading magnitude on a particular WE, a part of the forces should be equated to zero. The conditions corpus of the model adequacy to the loading of a particular WE has the following form:

- for the milling and drilling machines with the rigid rod

$\sin \alpha=1 ; \cos \alpha=1$

- for the milling and drilling machines with the flexible suspension [15]

$\sin \alpha=1 ; \cos \alpha=0 ; K_{b}=0 ;$

- $\quad$ for the drag line

$T^{y n}=0, P_{g d}^{y n}=0, M_{g d}^{\text {zn }}=0, M_{T}^{z y}=0$,

$K_{b}=0, P_{z}=0, P_{n}=0$

- for the dipper shovel with the rigid rod

$P_{e}=0, P_{n}=0, M_{g d}^{z y}=0, M_{T}^{z y}=0, T^{y n}=0$,

$P_{g s}^{y n}=0$;

- for the dipper shovel with the flexible suspension

$P_{e}=0, P_{n}=0, M_{g d}^{z y}=0, T^{y n}=0, P_{g d}^{y n}=0, K_{b}=0 ;$

- for the backhoe

$P_{e}=0, P_{n}=0, M_{g d}^{z y}=0, M_{T}^{z y}=0$.

Equations (42) - (45) do not comply with the study purpose. These equations are given to prove the model generalization in Equation (37).

The component forces analysis has shown that at the beginning of the work (at $\mathrm{z} \approx 0$ ), the conveyor reactive force has the greatest weight. As the penetration depth increases over 10 to $15 \mathrm{~m}$, the buoyancy force increases sharply, by an order of magnitude greater than the friction force of the rod against the mud. The moment from 
the resistance forces to the rotational motion of flat elements is also by an order of magnitude higher than the moment from the friction forces of cylindrical bodies against the mud during the rotational motion. Preliminary calculations based on the obtained dependences (Table 1), showed that when determining the resistance forces to the WE motion, the friction and the moment from the WE friction forces against the mud can be ignored.

As an example, the loading parameters of the milling WE of the UTF-1 (53) are calculated. The calculation was performed for the two conditions of the mud flow: Bingham and pseudo-laminar according to the following Equations (7), (12), (17), (23), (29), (32), (33) and (34), with the following parameters.

$\mathrm{Z}=\mathrm{y}=0, \mathrm{~V}=1 \mathrm{~m}^{3} \mathrm{~F}^{\mathrm{zn}}=\mathrm{F}^{\mathrm{yn}}=10 \mathrm{~m}^{2}$,

$\mathrm{F}^{\mathrm{zb}}=\mathrm{F}^{\mathrm{yb}}=1 \mathrm{~m}^{2}, \mathrm{~V}^{\mathrm{z}}=\mathrm{V}^{\mathrm{y}}=1 \cdot 10^{-2} \mathrm{M} / \mathrm{c}, \mathrm{V}_{\mathrm{n}}=1.5 \mathrm{~m} / \mathrm{s} \omega=3 \mathrm{c}^{-1}, \mathrm{R}=0.5 \mathrm{~m}$, $\rho_{c}=1.1 \cdot 10^{3} \mathrm{~kg} / \mathrm{m}^{3}$,

$\mathrm{F}_{c}=0.25 \mathrm{~m}^{2}, \tau_{0}=10 \mathrm{H} / \mathrm{m}^{2}, C_{d}^{n}=0.5, C_{d}^{B}=1, \mathrm{~L}=1 \mathrm{~m}, \mathrm{~F}=0.5 \mathrm{~m}^{2}$, $\mathrm{V}_{\mathrm{T}}=2 \mathrm{~m} / \mathrm{s}$.

Calculation of the loading parameters for the pseudolaminar flow conditions of the drilling mud has shown that for this case it is approximately 10 to $15 \%$ less than those given in the Table 2.

\section{Conclusions}

Due to the study result the following main conclusions have been made:

The greatest weighting in the total loading of the WE moving in the clay solution has a rotational moment from the resistance forces to the flat cells rotating, reactive force of conveyer and buoyancy force acting on the tool.

The results of experiments, using the SMF-2 testing device, have basically confirmed the dependences obtained analytically in determining the loading when moving the WE in the mud.

The moment due to the resistance forces to the WE moving in the clay solution must be calculated for the Bingham conditions, where the loading is the greatest. It is advisable to calculate the engine rated brake power using the pseudo-laminar conditions, since its parameters are close to the average maximum power parameters of the Bingham conditions.

\section{References}

[1] SAPIN, D. A. Settlement of the adjoining development during construction of trench slurry wall. Bulletin of Civil Engineers. 2014, 6(47), p. 133-139. ISSN 1999-5571.

[2] ANI, O. A., UZOEJINWA, B. B., EZEAMA, A. O., ONWUALU, A. P., UGWU, S. N., OHAGWU, C. J. Overview of soilmachine interaction studies in soil bins. Soil and Tillage Research [online]. 2018, 175, p. 13-27. ISSN 0167-1987. Available from: https://doi.org/10.1016/j.still.2017.08.002

[3] KAZAKOV, Y. N., BULANKIN, N. F. Experience of the device of bored piles of the increased bearing capacity. Foundations and Soil Mechanics. 2015, 1, p. 15-17. ISSN 0038-0741, eISSN1573-9279.

[4] GRIGULETSKY, V. G., SAVELYEV, Y. P. Dynamic and thermal fields in turbulent flow of drilling mud in the annular space of pipes. Oil, Gas and Business. 2016, 10, p. 3-21. ISSN 2218-4929.

[5] KOCHETKOVA, R. G. Influence of modern stabilizers on improved properties of clayey soils. Soil Mechanics and Foundation Engineering[online]. 2012, 49(1), p. 12-15. ISSN 0038-0741, eISSN 1573-9279. Available from: https://doi.org/10.1007/s11204-012-9160-1

[6] ALIEV, S. B., SULEEV, B. D. Study and calculation of the disk-milling tool. Ugol- Russian Coal Journal[online]. 2018, 11, p. 32-34. ISSN 0041-5790, eISSN 2412-8333. Available from: http://dx.doi.org/10.18796/0041-5790-2018-11-32-34

[7] ZHUNUSBEKOVA, Z. Z., KADYROV, A. S. Study of digging machine flat element loading in clay solution. Scientific Bulletin of National Mining University in Dnipropetrovsk. 2016, 2(152), p. 30-34. ISSN 2071-2227.

[8] KADYROV, A. S., AMANGELDIEV, N. E. New specifications of the theory of ground cutting. Periodico Tche Quimica. 2019, 16(31), p. 922-936. ISSN 1806-0374, eISSN 2179-0302.

[9] MEDVEDEVSKIKH, Y. G., KHAVUNKO, O. Y., BAZYLYAK, L. I., ZAIKOV, G. E. Viscoelastic properties of the polystyrene in concentrated solutions and melts (Part 1). Bulletin of Kazan Technological University. 2012, 1, p. 155-164. ISSN 1998-7072.

[10] BALOVNEV, V. I., DANILOV, R. G. New methods for calculating resistance of soils innovative cutting working tools. Mechanization of Construction. 2016, 77(7), p. 5-13. ISSN 0025-8903, eISSN2409-7594.

[11] SEMENOV, A. V., VAKHRUSHEV, S. I., TRENOGIN, E. O. Research of mathematical models of certain working operations, which are making up machine working cycle. Master's journal of Perm National Research Polytechnic University. 2016, 2, p. 379-390. ISSN 2306-8590, eISSN 2306-8604.

[12] POLOVOV, B. D., HIMICH, A. A., VALIEV, N. G. Fundamentals of mining: General information and concepts of mining. underground, open and construction geotechnologies. Textbook for Universities. Yekaterinburg: FGBOU VPO "Ural state mining University", 2012.

[13] PALGUEV, I. P. Drilling rigs AO "Stroydormash" for construction of pile foundations. Construction and Road Vehicles. 2017, 6, p. 45-50. ISSN 0039-2391 
[14] DULOVA, M. B. Dynamic analysis of working equipment of boring machine in the process of well-drilling. Reshetnev Siberian State Aerospace University. 2016, 12, p. 352-354. ISSN 1816-9724.

[15] SHEROV, K. T., KHODZHIBERGENOV, D. T., ESIRKEPOV, A. Drilling method and construction of a combined drill-mill bit. Russian Engineering Research. 2019. 39, No 8. p. 665-668. ISSN: 1068-798X 